M.Yu. Artemenko, L.M. Batrak, S.Y. Polishchuk

\title{
CURRENT FILTERING IN A THREE-PHASE THREE-WIRE POWER SYSTEM AT ASYMMETRIC SINUSOIDAL VOLTAGES
}

\begin{abstract}
Purpose. Investigation of the optimal current distribution between source, shunt active filter and reactive compensator of a three-phase three-wire system that provides consumption of a sinusoidal symmetric current under asymmetric source voltages with minimal power losses was provided. Methodology. The tasks were solved by conducting theoretical and experimental studies. The main provisions of the theory of electrical circuits, the apparatus of mathematical analysis, methods for solving linear differential and algebraic equations, elements of matrix and complex calculus and vector algebra are used. During the development, modern methods and software of computer simulation of electrical engineering complexes and dynamic systems were applied: Matlab-Simulink, MATHCAD. Originality. The principle of compensating current distribution between $P A F$ and reactive compensator of a three-phase three-wire power system with asymmetric sinusoidal voltage was proposed at which the input current is equal to the positive-sequence active current and rms value of PAF current is minimal. The feasibility to compensate the inactive sinusoidal Fryze current by reactive elements under arbitrary combination of load and source parameters was proved and expression for direct calculation of the reactive compensator parameters for generation of inactive Fryze current in the source unbalanced mode was obtained. Practical value. The simulative example for transmission line load showed that combined application of PAF and reactive compensator with the specified distribution of compensating currents ensured a reduction of power losses in 3.273 times and rms value of the $S A F$ current is $12.9 \%$ of rms value total compensation current. References 10, tables 1 , figures 2.

Key words: active and inactive Fryze current, asymmetrical voltage and load, reactive compensator, symmetrical components.
\end{abstract}

Рассмотрены принципы активной фильтрации тока в трехфазной трехпроводной системе электропитания при несимметричном синусоидальном источнике питания, удовлетворяющие требованиям стандарта IEEE Std.14592010. Показаны преимущества формирования синусоидального симметричного входного тока при параллельном подключении активного фильтра и реактивного компенсатора. Доказана возможность компенсации неактивного синусоидального тока Фризе реактивными элементами при произвольной комбинации параметров нагрузки и источника. Получена формула прямого расчета параметров реактивного компенсатора для генерации неактивного тока Фризе в несимметричном режсиме источника питания. Приводятся результаты численного моделирования. Библ. 10, табл. 1, рис. 2.

Ключевые слова: активный и неактивный ток Фризе, несимметричное напряжение и нагрузка, реактивный компенсатор, симметричные составляющие.

Introduction. The unbalanced load of three-phase, three-wire power systems leads to a deterioration in the quality of electricity, which manifests in the emergence of negative sequence currents and pulsations of instantaneous power, which cause additional losses on the active supports of the transmission line and asymmetry of the supply voltages in the nodes of the overall connection of loads. Passive filters on reactive elements are efficiently used to balance the asymmetrical stationary linear load, calculation of which is based on two approaches: compensation of inactive components of input currents [1, 3-5] and elimination of the pulsating component of instantaneous power $[2,6]$. However, in the case of asymmetry of voltages, the use of passive reactive compensators of both types leads to the emission into the transmission line of negative sequence currents and even greater voltage asymmetry, which contradicts the approaches outlined in [7]. Effective compensation of these currents is possible only by means of active filtration [8], and parallel active filters (PAF) are dominated successive ones by power of energy losses on their own elements. To further reduce the loss of PAF they are used in combination with reactive compensators [9]. Therefore, it is relevant to study the optimal distribution of asymmetric load currents between a threephase source, PAF and a reactive compensator, which provides the minimum power loss when consuming sinusoidal symmetric source current.
Vectors of active currents in phase coordinates. The periodic process in the section $\langle A, B, C>$ of the threewire power supply system is determined by threecoordinate vectors of instantaneous voltage and current values

$$
\begin{gathered}
\boldsymbol{u}(t)=\left\|\begin{array}{l}
u_{A}(t) \\
u_{B}(t) \\
u_{C}(t)
\end{array}\right\|=\sqrt{2}\left\|\begin{array}{l}
U_{A} \cos \left(\omega t+\phi_{A}\right) \\
U_{B} \cos \left(\omega t+\phi_{A}\right) \\
U_{C} \cos \left(\omega t+\phi_{A}\right)
\end{array}\right\| ; \\
\boldsymbol{i}(t)=\left\|\begin{array}{c}
i_{A}(t) \\
i_{B}(t) \\
i_{C}(t)
\end{array}\right\|=\boldsymbol{i}(t+2 \pi / \omega),
\end{gathered}
$$

where $\omega$ is the circular frequency of the three-phase source; $u_{A}, u_{B}, u_{C}$ are the phase voltages deduced from the point of artificial grounding [5], $U_{A}, U_{B}, U_{C}$ and $\varphi_{A}, \varphi_{B}$, $\varphi_{C}$ are their mean square and initial phases; the periodic current vector $\boldsymbol{i}(t)$ contains higher harmonic components in the case of nonlinear loading.

According to the Fryze [1] concept, active current

$$
\boldsymbol{i}_{A}(t)=\frac{P}{U^{2}} \boldsymbol{u}(t)
$$

provides the same active power $P$ as the total current $\boldsymbol{i}(t)$.

The scalar coefficients of formula (2) can be found in the time domain as integrals 


$$
\begin{gathered}
P=\frac{1}{T} \int_{0}^{T} \boldsymbol{u}^{\wedge}(t) \boldsymbol{i}(t) d t \\
U^{2}=\frac{1}{T} \int_{0}^{T} \boldsymbol{u}^{\wedge}(t) \boldsymbol{u}(t) d t=U_{A}^{2}+U_{B}^{2}+U_{C}^{2} ;
\end{gathered}
$$

where $\wedge$ is the sign of transposition, $T=2 \pi / \omega$ is the period.

The current determined by the formula

$$
\boldsymbol{i}_{N}(t)=\boldsymbol{i}(t)-\boldsymbol{i}_{A}(t),
$$

is called inactive [1], it does not carry energy to load, but causes additional losses in the transmission line.

Since the vectors of active and inactive currents are mutually orthogonal, the correct ratio for the mean square values of these currents is:

$$
I^{2}=\frac{1}{T} \int_{0}^{T} \boldsymbol{i}^{\wedge}(t) \boldsymbol{i}(t) d t=I_{A}^{2}+I_{N}^{2} .
$$

In the case of compensation of inactive current by means of filtration, we will have a decrease in the power loss $\Delta P$ in the transmission line, which can be characterized [10] by the coefficient of gain on the power loss:

$$
k_{A}^{\Delta P}=\frac{\Delta P}{\Delta P_{A}}=\frac{I^{2} r}{I_{A}^{2} r}=\frac{1}{\lambda^{2}},
$$

where $r$ is the resistance of each wire of the transmission line; $\lambda=P / S=I_{A} / I$ is the power factor; $S=U I$ is the full power of the three-phase system.

In the sinusoidal mode of the three-phase voltage source, the active current vector also consists of sinusoidal temporal functions, so it is expedient [5] to introduce three-dimensional complex vectors (3Dphasors) of voltage and current in the same way [5].

$$
\begin{aligned}
& \overline{\boldsymbol{u}}=\frac{\sqrt{2}}{T} \int_{0}^{T} \boldsymbol{u}(t) e^{-j \omega t} d t=\left\|\begin{array}{c}
U_{A} e^{j \varphi_{A}} \\
U_{B} e^{j \varphi_{A}} \\
U_{C} e^{j \varphi_{A}}
\end{array}\right\|=\left\|\begin{array}{l}
\dot{U}_{A} e^{j \varphi_{A}} \\
\dot{U}_{B} e^{j \varphi_{A}} \\
\dot{U}_{C} e^{j \varphi_{A}}
\end{array}\right\| ; \\
& \overline{\boldsymbol{i}}_{1}=\frac{\sqrt{2}}{T} \int_{0}^{T} \boldsymbol{i}(t) e^{-j \omega t} d t=\left\|\begin{array}{l}
\dot{I}_{A} e^{j \psi_{A}} \\
\dot{I}_{B} e^{j \psi_{A}} \\
\dot{I}_{C} e^{j \psi_{A}}
\end{array}\right\| \text {. }
\end{aligned}
$$

The complex vector $\overline{\boldsymbol{i}}_{1}$ represents the harmonic component of the fundamental frequency of the vector $\boldsymbol{i}(t)$. In the time domain, it corresponds to a vector of instantaneous values $\boldsymbol{i}_{1}(t)$, which differs from the vector $\boldsymbol{i}(t)$ on the vector of higher harmonics

$$
\boldsymbol{i}_{H}(t)=\boldsymbol{i}(t)-\boldsymbol{i}_{1}(t)=\boldsymbol{i}(t)-\sqrt{2} \operatorname{Re}\left(\overline{\boldsymbol{i}}_{1} e^{j \omega t}\right) .
$$

However, two complex vectors of (5) completely determine the active Fryze current in the frequency domain:

$\overline{\boldsymbol{i}}_{A}=\frac{\sqrt{2}}{T} \int_{0}^{T} \boldsymbol{i}_{A}(t) e^{-j \omega t} d t=\frac{P}{U^{2}} \overline{\boldsymbol{u}}=\frac{\operatorname{Re}\left(\overline{\boldsymbol{u}}^{\wedge} \overline{\boldsymbol{i}}_{1}^{*}\right)}{\overline{\boldsymbol{u}}^{\wedge} \overline{\boldsymbol{u}}^{*}} \overline{\boldsymbol{u}}=\overline{\boldsymbol{i}}_{1}-\boldsymbol{i}_{1 N}$, where the sign $*$ denotes complex conjugation, $\overline{\boldsymbol{i}}_{1 N}$ is the complex vector of inactive current of the main frequency.

In the unbalanced mode of the three-phase source, the vectors $\overline{\boldsymbol{u}}$ and $\overline{\boldsymbol{i}}_{A}$ contain symmetric components of the negative sequence, which the modern Standard [7] refers to inactive components of the current to be compensated. To meet the requirements of the Standard, the active current must be formed as proportional to the reference voltage vector containing only the symmetric components of the direct sequence. We represent this vector in the frequency domain as proportional to the ort of a symmetric direct sequence [5]

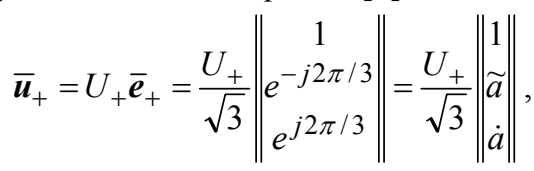

then the active current vector of the direct sequence is given by the expression

$$
\overline{\boldsymbol{i}}_{A+}=\frac{P}{\overline{\boldsymbol{u}}_{+}^{\wedge} \overline{\boldsymbol{u}}_{+}^{*}} \overline{\boldsymbol{u}}_{+}=\frac{P}{U_{+}^{2}} \overline{\boldsymbol{u}}_{+},
$$

where the coefficient of proportionality is determined from the condition of providing by this current under the action of the voltage vector $\overline{\boldsymbol{u}}$ of the same active power $P$, as the total current $\boldsymbol{i}(t)$.

Decomposition of load currents in symmetric coordinates. For a detailed study of the difference between the vectors defined by formulas (7) and (9), we turn to the basis of symmetric coordinates [5]. Since the symmetric component of the zero sequence of each of these vectors is zero, we multiply them on the matrix containing the transposed orts of the symmetric components of the direct and negative sequences

$$
\left(\boldsymbol{F}_{0}^{\wedge}\right)^{*}=\left\|\begin{array}{l}
\overline{\boldsymbol{e}}_{-}^{\wedge} \\
\overline{\boldsymbol{e}}_{+}^{\wedge}
\end{array}\right\|=\frac{1}{\sqrt{3}}\left\|\begin{array}{ccc}
1 & \dot{a} & \tilde{a} \\
1 & \tilde{a} & \dot{a}
\end{array}\right\| .
$$

As a result, we obtain the following expressions for complex voltage vectors in symmetric coordinates:

$$
\begin{gathered}
\tilde{\boldsymbol{u}}_{+}=\left(\boldsymbol{F}_{0}^{\wedge}\right)^{*} \overline{\boldsymbol{u}}_{+}=\left\|\begin{array}{c}
\overline{\boldsymbol{e}}_{-}^{\wedge} \| \\
\overline{\boldsymbol{e}}_{+}^{\wedge}
\end{array}\right\| U_{+} \overline{\boldsymbol{e}}_{+}=\left\|\begin{array}{c}
U_{+} \\
0
\end{array}\right\| ; \\
\tilde{\boldsymbol{u}}=\left(\boldsymbol{F}_{0}^{\wedge}\right)^{*} \overline{\boldsymbol{u}}=\left(\boldsymbol{F}_{0}^{\wedge}\right)^{*}\left\|\begin{array}{c}
\dot{U}_{A} \\
\dot{U}_{B} \\
\dot{U}_{C}
\end{array}\right\|=\| \begin{array}{l}
U_{+} \| \\
\dot{U}_{-} \|
\end{array}
\end{gathered}
$$

The transition from two-coordinate vectors in symmetric coordinates to three-coordinate complex vectors in phase coordinates is carried out by multiplying on the matrix $\boldsymbol{F}_{0}=\left\|\overline{\boldsymbol{e}}_{+} \quad \overline{\boldsymbol{e}}_{-}\right\|$. Taking into account the relationship between the matrices

$$
\left(\boldsymbol{F}_{0}^{\wedge}\right)^{*} \boldsymbol{F}_{0}=\left\|\begin{array}{cc}
1 & 0 \\
0 & 1
\end{array}\right\|=\boldsymbol{I}_{2 \times 2} ; \quad \boldsymbol{F}_{0}\left(\boldsymbol{F}_{0}^{\wedge}\right)^{*}=\boldsymbol{I}_{3 \times 3}-\frac{\boldsymbol{j j}^{\wedge}}{3} ; \boldsymbol{j}=\|1\|,
$$

which stores the mean square values of the quantities in symmetric and phase coordinates, we obtain the following 
expressions for complex active current vectors in symmetric coordinates

$$
\begin{gathered}
\tilde{\boldsymbol{i}}_{A}=\frac{P}{\overline{\boldsymbol{u}}^{\wedge} \overline{\boldsymbol{u}}^{*}} \widetilde{\boldsymbol{u}}=\frac{P}{\widetilde{\boldsymbol{u}}^{\wedge} \tilde{\boldsymbol{u}}^{*}} \widetilde{\boldsymbol{u}}=\frac{P}{U_{+}^{2}+U_{-}^{2}}\left\|\begin{array}{l}
U_{+} \\
\dot{U}_{-}
\end{array}\right\| ; \\
\tilde{\boldsymbol{i}}_{A_{+}}=\frac{P}{U_{+}^{2}} \tilde{\boldsymbol{u}}_{+}=\frac{P}{U_{+}^{2}}\left\|\begin{array}{c}
U_{+} \\
0
\end{array}\right\| .
\end{gathered}
$$

Consumption from an asymmetric sinusoidal Fryze current source does not eliminate the pulsations of active power [5]. Its instantaneous value can be determined [2] using the vector

$$
\tilde{\boldsymbol{i}}_{A}^{\leftrightarrow}=\frac{P}{U_{+}^{2}+U_{-}^{2}}\left\|\begin{array}{l}
\dot{U}_{-} \\
U_{+}
\end{array}\right\|
$$

by the formula

$$
\begin{aligned}
& \tilde{p}_{A}(t)=\operatorname{Re}\left(\tilde{\boldsymbol{u}}^{\wedge} \tilde{\boldsymbol{i}}_{A} \leftrightarrow e^{j 2 \omega t}\right)=\frac{P \operatorname{Re}\left(2 U_{+} \dot{U}_{-} e^{j 2 \omega t}\right)}{U_{+}^{2}+\dot{U}_{-}^{2}}= \\
& =\frac{2 P \delta_{-} \cos \left(2 \omega t+\varphi_{-}\right)}{1+\delta_{-}^{2}},
\end{aligned}
$$

where $\dot{\delta}_{-}=\dot{U}_{-} / \dot{U}_{+}=\delta_{-} e^{j \varphi_{-}}$is the complex parameter of asymmetry of a three-phase source.

If the input current of the three-phase system is determined by the vector $\tilde{\boldsymbol{i}}_{A}$, the instantaneous value of the pulsation of the active power is

$$
\begin{aligned}
& \tilde{p}_{A+}(t)=\operatorname{Re}\left(\tilde{\boldsymbol{u}}^{\wedge} \tilde{\boldsymbol{i}}_{A+}^{\leftrightarrow} e^{j 2 \omega t}\right)=\frac{P}{U_{+}^{2}} \operatorname{Re}\left(\left\|U_{+} \dot{U}_{-}\right\|\left\|_{U_{+}}\right\| e^{j 2 \omega t}\right)= \\
& =P \delta_{-} \cos \left(2 \omega t+\varphi_{-}\right) .
\end{aligned}
$$

Thus, the active current of a direct sequence creates a pulsation of instantaneous power, the amplitude of which is in $2 /\left(1+\delta_{-}^{2}\right)$ times less than that one generated by the active Fryze current.

The difference between the active current vectors in symmetric coordinates obtained from (10), i.e.

$$
\tilde{\boldsymbol{i}}_{ \pm}=\tilde{\boldsymbol{i}}_{A}-\tilde{\boldsymbol{i}}_{A+}=\frac{P}{U_{+}^{2}+U_{-}^{2}}\left\|\begin{array}{c}
-U_{-}^{2} / U_{+} \\
\dot{U}_{-}
\end{array}\right\|
$$

defines an additional current of compensation. The active power of this current is zero:

$$
P_{ \pm}=\operatorname{Re}\left(\tilde{\boldsymbol{u}}^{\wedge} \widetilde{\boldsymbol{i}}_{ \pm}^{*}\right)=\left(\frac{P}{U_{+}^{2}+U_{-}^{2}}\right)^{2}\left\|U_{+} \quad \dot{U}_{-}\right\|\left\|\begin{array}{c}
-U_{-}^{2} / U_{+} \|=0, \\
\tilde{U}_{-}
\end{array}\right\|=
$$

and it can be realized by PAF.

Thus, in order to realize the consumption from a three-phase current source of current active current of direct sequence, the main harmonic of the compensation current should contain the following components in symmetric coordinates:

$$
\tilde{\boldsymbol{i}}_{1 C}=\boldsymbol{i}_{1}-\boldsymbol{i}_{A+}=\boldsymbol{i}_{1 N}+\boldsymbol{i}_{ \pm}
$$

In the time domain, the compensation current vector also includes a higher harmonic vector:

$$
\boldsymbol{i}_{C_{+}}(t)=\boldsymbol{i}(t)-\boldsymbol{i}_{A+}(t)=\boldsymbol{i}_{1 N}(t)+\boldsymbol{i}_{ \pm}(t)+\boldsymbol{i}_{H}(t) .
$$

The coefficient of gain on the power loss in the formation of active current of direct sequence

$$
k_{A+}^{\Delta P}=\frac{\Delta P}{\Delta P_{A+}}=\frac{I^{2}}{I_{A+}^{2}}=\frac{I_{A}^{2}+I_{N}^{2}}{I_{A}^{2}} \times \frac{I_{A}^{2}}{I_{A+}^{2}}=\frac{k_{A}^{\Delta P}}{1+\delta_{-}^{2}}
$$

exceeds the unit provided

$$
\lambda \sqrt{1+\delta_{-}^{2}}<1
$$

Taking into account the orthogonality of the vectors $\boldsymbol{i}_{C+}(t), \boldsymbol{i}_{A+}(t)$ and the limitation (15), the relative mean square value of the compensation current

$$
\frac{I_{C+}^{2}}{I^{2}}=\frac{I^{2}-I_{A+}^{2}}{I^{2}}=1-\frac{1}{k_{A+}^{\Delta P}}=1-\lambda^{2}\left(1+\delta_{-}^{2}\right) .
$$

At low values of the power factor, the rms value of the compensation current increases. To reduce the power loss of the active filter, it is advisable to use $\mathrm{PAF}$ in combination with a passive reactive compensator [9].

Current filtering for linear stationary load. If the load is linear and not changeable in time, then in formula (13) $\boldsymbol{i}_{H}(t)=0$, and all components of the currents are sinusoidal in the time domain, then the energy processes in the system are completely determined in the basis of symmetric coordinates. In this case, the compensation current vector corresponds to (12), and the sinusoidal inactive current can be completely generated by the reactive compensator in both the symmetric and asymmetric mode of the voltage source [5]. Therefore, in order to minimize the loss of PAF power, it is advisable to distribute the currents of the reactive compensator and the active filter in the integrated substitution circuit (Fig. 1) as follows:

$$
\overline{\boldsymbol{i}}_{R}=\left\|\begin{array}{c}
\dot{I}_{A}^{R} \| \\
\dot{I}_{B}^{R} \\
\dot{I}_{C}^{R}
\end{array}\right\|=\boldsymbol{F}_{0} \widetilde{\boldsymbol{i}}_{1 N} ; \quad \overline{\boldsymbol{i}}_{F}=\left\|\begin{array}{l}
\dot{I}_{A}^{F} \\
\dot{I}_{C}^{F} \\
\dot{I}_{C}^{F}
\end{array}\right\|=\boldsymbol{F}_{0} \widetilde{\boldsymbol{i}}_{ \pm}
$$

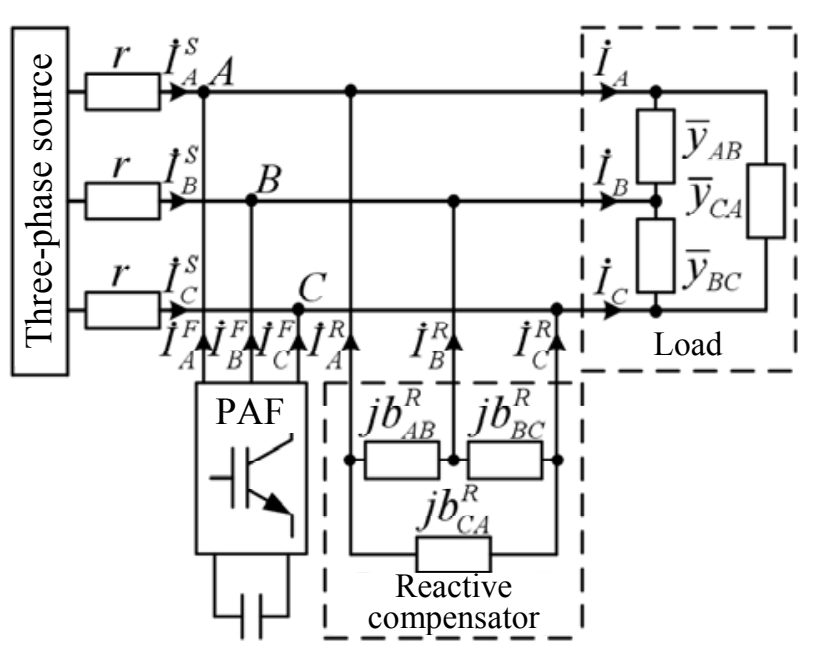

Fig. 1. The substitution circuit

This will reduce the mean square value of the PAF currents to the value

$$
I_{F}=\sqrt{\widetilde{\tilde{\boldsymbol{i}}_{ \pm}^{\wedge} \widetilde{\boldsymbol{i}}_{ \pm}^{*}}}=\frac{P U_{-}}{U_{+} \sqrt{U_{+}^{2}+U_{-}^{2}}}=\frac{P \delta_{-}}{U_{+} \sqrt{1+\delta_{-}^{2}}} .
$$


We obtain the formulas for the direct calculation of the parameters of the reactive compensator for the generation of the inactive Fryze current in the asymmetric mode of the three-phase source. Let the linear stationary load be characterized by a diagonal matrix of complex conductivities

$\overline{\boldsymbol{Y}}=\left\|\begin{array}{ccc}\bar{y}_{A B} & 0 & 0 \\ 0 & \bar{y}_{B C} & 0 \\ 0 & 0 & \bar{y}_{C A}\end{array}\right\|=\left\|\begin{array}{ccc}g_{A B} & 0 & 0 \\ 0 & g_{B C} & 0 \\ 0 & 0 & g_{C A}\end{array}\right\|+j\left\|\begin{array}{ccc}b_{A B}^{L} & 0 & 0 \\ 0 & b_{B C}^{L} & 0 \\ 0 & 0 & b_{C A}^{L}\end{array}\right\|$.

In [5] it was shown that the Ohm law for input vectors of current and voltage is described by an expression in symmetric coordinates

$$
\tilde{\boldsymbol{i}}=\tilde{\boldsymbol{Y}} \tilde{\boldsymbol{u}}=\left(\left\|\begin{array}{cc}
g_{+} & \dot{g} \\
\widetilde{g} & g_{+}
\end{array}\right\|+j\left\|\begin{array}{cc}
b_{+}^{L} & \dot{b}_{L} \\
\tilde{b}_{L} & b_{+}^{L}
\end{array}\right\|,\right) \tilde{\boldsymbol{u}},
$$

where

$$
\begin{aligned}
& g_{+}+j b_{+}^{L}=\bar{y}_{A B}+\bar{y}_{B C}+\bar{y}_{C A} ; \tilde{g}=(\dot{g})^{*} ; \tilde{b}_{L}=-\left(\dot{b}_{L}\right)^{*} ; \\
& \dot{g}=-\left(\dot{a} g_{A B}+g_{B C}+\tilde{a} g_{C A}\right) ; \quad \dot{b}_{L}=-\left(\dot{a} b_{A B}^{L}+b_{B C}^{L}+\tilde{a} b_{C A}^{L}\right) .
\end{aligned}
$$

Similar parameters of the jet compensator $b_{+}^{R}=b_{A B}^{R}+b_{B C}^{R}+b_{C A}^{R} ; \quad \dot{b}_{R}=-\left(\dot{a} b_{A B}^{R}+b_{B C}^{R}+\widetilde{a} b_{C A}^{R}\right) \quad$ for realization of the compensation current vector $\tilde{\boldsymbol{i}}_{C}=\left\|\begin{array}{ll}I_{+}^{C} & I_{+}^{C}\end{array}\right\|^{\wedge}$ are determined by the matrix-vector equation [5]:

$$
\left\|\begin{array}{c}
b_{+}^{R} \\
\dot{b}_{R}
\end{array}\right\|=\frac{j}{U_{+}^{2}-U_{-}^{2}}\left\|\begin{array}{cc}
U_{+} & -U_{-} \\
-\widetilde{U}_{-} & U_{+}
\end{array}\right\| \begin{gathered}
\dot{I}_{+}^{C} \\
-\widetilde{I}_{-}^{C}
\end{gathered} \| .
$$

We show that for a compensation currents vector in the form of an inactive Fryze current

$$
\tilde{\boldsymbol{i}}_{C}=\tilde{\boldsymbol{i}}_{1 N}=\tilde{\boldsymbol{Y}} \tilde{\boldsymbol{u}}-\tilde{\boldsymbol{i}}_{A}=\left(\tilde{\boldsymbol{Y}}-\frac{P}{U_{+}^{2}+U_{-}^{2}} \boldsymbol{I}_{2 \times 2}\right) \tilde{\boldsymbol{u}}
$$

the parameter $b_{+}^{R}$. will always be a real number. For this we find the expression for the active power of the given load

$$
P=\operatorname{Re}\left(\tilde{\boldsymbol{i}}^{\wedge} \widetilde{\boldsymbol{u}}^{*}\right)=\operatorname{Re}\left(\tilde{\boldsymbol{u}}^{\wedge} \tilde{\boldsymbol{Y}}^{\wedge} \tilde{\boldsymbol{u}}^{*}\right)=\left(g_{+}+\Delta g\right)\left(U_{+}^{2}+U_{+}^{2}\right),
$$

where $\Delta g=2 U_{+} \operatorname{Re}\left(\dot{g} \dot{U}_{-}\right) /\left(U_{+}^{2}+U_{+}^{2}\right)=2 \operatorname{Re}\left(\dot{\delta}_{-} \dot{g}\right) /\left(1+\delta_{-}^{2}\right)$, and substitute this expression in formula (17) and further in (16).

After the transformation we have

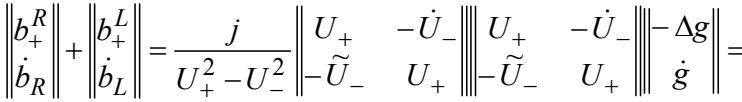

$$
\begin{aligned}
& =\frac{1}{1-\delta_{-}^{2}}\left\|j\left[\begin{array}{c}
-2 \operatorname{Im}\left(\dot{\delta}_{-} \dot{g}\right) \\
2 \tilde{\delta}_{-} \Delta g-\left(1+\delta_{-}^{2}\right) \dot{g}
\end{array}\right]=\right\| \begin{array}{c}
b_{+} \\
\dot{b}
\end{array} \| .
\end{aligned}
$$

The first coordinates of the vectors of formula (18) are real numbers, which proves the possibility of realizing the reactive compensator of the inactive Fryze current at an arbitrary combination of linear load parameters and an asymmetric source. The reactive conductivities of the compensator are determined from the system of equations (18) in the form

$$
\begin{aligned}
& b_{A B}^{R}=\frac{b_{+}-2 \operatorname{Re}(\tilde{a} \dot{b})}{3}-b_{A B}^{L} ; \\
& b_{B C}^{R}=\frac{b_{+}-2 \operatorname{Re}(\dot{b})}{3}-b_{B C}^{L} ; \\
& b_{C A}^{R}=\frac{b_{+}-2 \operatorname{Re}(\dot{a} \dot{b})}{3}-b_{C A}^{L} .
\end{aligned}
$$

Example of simulation of currents filtration. We consider the hybrid filtration of input currents for a threewire linear load determined by complex conductivities

$$
\begin{gathered}
\bar{Y}_{A B}=\frac{G}{4+j 3}=(0.16-j 0.12) G ; \bar{Y}_{B C}=0 ; \\
\bar{Y}_{B C}=\frac{G}{1-j}=(0.5+j 0.5) G,
\end{gathered}
$$

and the asymmetry of the source is characterized by the parameter $\dot{\delta}_{-}=0.2 j$.

First of all, we define the parameters of the matrix of complex conductivities in symmetric coordinates

$$
\begin{gathered}
g_{+}=g_{A B}+g_{B C}+g_{C A}=(0.16+0.5) G=0.66 G ; \\
b_{+}^{L}=b_{A B}^{L}+b_{B C}^{L}+b_{C A}^{L}=(-0.12+0.5) G=0.38 G ; \\
\dot{g}=-\left(\dot{a} g_{A B}+g_{B C}+\widetilde{a} g_{C A}\right)=(0.33+0.294 j) G ; \\
\dot{b}_{L}=-\left(\dot{a} b_{A B}^{L}+b_{B C}^{L}+\widetilde{a} b_{C A}^{L}\right)=(0.19+0.537 j) G .
\end{gathered}
$$

The values of the matrix of complex conductivities in accordance with (16)

$$
\widetilde{\boldsymbol{Y}}=\widetilde{\boldsymbol{G}}+j \widetilde{\boldsymbol{B}}_{L}=\left\|\begin{array}{cc}
0.66+0.38 j & -0.207+0.484 j \\
0.867-0.104 j & 0.66+0.38 j
\end{array}\right\| G
$$

The load current vector

$$
\tilde{\boldsymbol{i}}=\tilde{\boldsymbol{Y}} \widetilde{\boldsymbol{u}}=\tilde{\boldsymbol{Y}}\left\|\begin{array}{c}
1 \\
0.2 j
\end{array}\right\| U_{+}=\left\|\begin{array}{l}
0.563+0.339 j \\
0.791+j 0.028
\end{array}\right\| U_{+} G .
$$

We determine the parameter

$$
\Delta g=\frac{2 \operatorname{Re}\left(\delta_{-} \dot{g}\right)}{1+\delta_{-}^{2}}=-0.113 G
$$

and find the Fryze active current vector:

$$
\tilde{\boldsymbol{i}}_{A}=\frac{P}{U_{+}^{2}+U_{-}^{2}} \tilde{\boldsymbol{u}}=\left(g_{+}+\Delta g\right) \tilde{\boldsymbol{u}}=\left\|\begin{array}{c}
0.547 \\
0.109 j
\end{array}\right\| U_{+} G .
$$

The value of the power factor

$$
\lambda=I_{A} / I=\sqrt{\tilde{\boldsymbol{i}}_{A} \hat{\boldsymbol{i}}_{A}^{*} / \tilde{\boldsymbol{i}}^{\wedge} \widetilde{\boldsymbol{i}}^{*}}-=0.542
$$

satisfies the condition (15):

$$
\lambda \sqrt{1+U_{-}^{2} / U_{+}^{2}}=\lambda \sqrt{1+\delta_{-}^{2}}=0.553<1 .
$$

Consequently, in accordance with (14), the formation of the active current of a direct sequence will bring savings in energy losses, which is estimated by the coefficient of gain

$$
k_{A+}^{\Delta P}=1 / 0.553^{2}=3.273 .
$$

Further by (18) we determine the parameters of the reactive compensator:

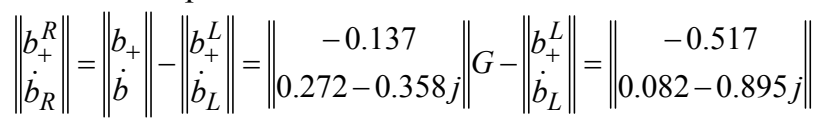

and form a matrix of complex conductivities with elements of reactive compensation: 


$$
\widetilde{\boldsymbol{Y}}_{R}=\tilde{\boldsymbol{Y}}+j\left\|\begin{array}{cc}
b_{+}^{R} & \dot{b}_{R} \\
\tilde{b}_{R} & b_{+}^{R}
\end{array}\right\|=\left\|\begin{array}{cc}
0.66-0.137 j & 0.688+0.566 j \\
-0.028-0.022 j & -0.66-0.137 j
\end{array}\right\| G
$$

The multiplication of this matrix on the vector of the input voltage gives the vector of the input current in the presence of a reactive compensator

$$
\widetilde{\boldsymbol{i}}_{S R}=\widetilde{\boldsymbol{Y}}_{R} \tilde{\boldsymbol{u}}=\left\|\begin{array}{l}
0.547 \\
0.109
\end{array}\right\| U_{+} G,
$$

which completely coincides with the previously determined vector of Fryze active current, which indicates the correctness of the calculation of the parameters of the compensator.

Generation of PAF of the vector of current determined by (11)

$$
\tilde{\boldsymbol{i}}_{F}=\tilde{\boldsymbol{i}}_{ \pm}\left(g_{+}+\Delta g\right)\left\|\begin{array}{c}
-0.04 \\
0.2 j
\end{array}\right\| U_{+}=\left\|\begin{array}{c}
-0.022 \\
0.109 j
\end{array}\right\|
$$

provides the consumption from a three-phase source of active current vector of direct sequence:

$$
\tilde{\boldsymbol{i}}_{S F R}=\tilde{\boldsymbol{i}}_{A+}=\tilde{\boldsymbol{i}}_{A}-\tilde{\boldsymbol{i}}_{ \pm}=\left\|\begin{array}{c}
0.569 \\
0
\end{array}\right\| U_{+} G .
$$

The joint action of PAF and reactive compensator provides a total compensation current

$$
\tilde{\boldsymbol{i}}_{C+}=\tilde{\boldsymbol{i}}-\widetilde{\boldsymbol{i}}_{A+}=\left\|\begin{array}{c}
-0.006+0.339 j \\
0.791+j 0.028
\end{array}\right\| U_{+} G,
$$

thus the relative active value of PAF currents is

$$
I_{F} / I_{C+}=\sqrt{\tilde{\boldsymbol{i}}_{F}^{\wedge} \widetilde{\boldsymbol{i}}_{F}^{*} / \widetilde{\boldsymbol{i}}_{C+}^{\wedge} \tilde{\boldsymbol{i}}_{C+}^{*}}=0.129=12.9 \% \text {. }
$$

The reactive conductivities of the compensator are calculated by (19):

$$
b_{A B}^{R}=0.371 G ; \quad b_{B C}^{R}=-0.227 G ;
$$

Simulation of currents filtration in the time domain was carried out using the MATLAB model presented in Fig. 2

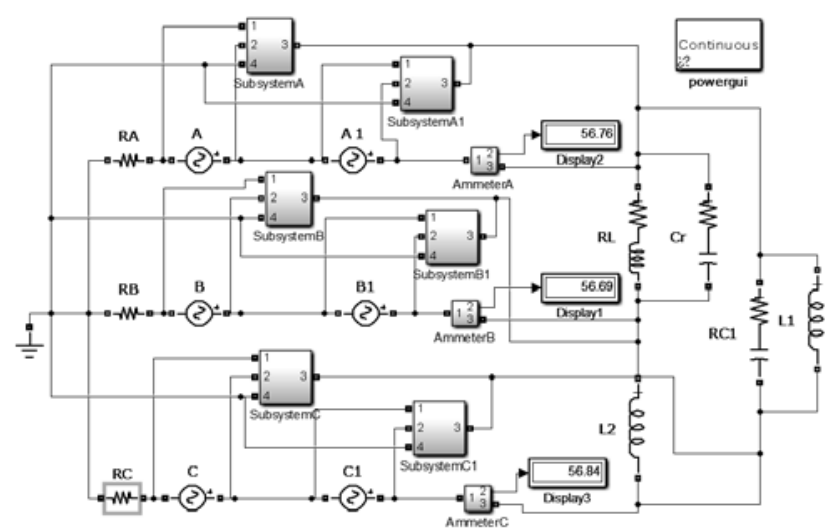

Fig. 2

Parameters of the reactive elements of the compensator for $G=1 \mathrm{~S}$ and $\omega=100 \pi \mathrm{rad} / \mathrm{s}$ are, respectively, $C_{A B}=1.18 \mathrm{mF} ; L_{B C}=14.02 \mathrm{mH} ; L_{C A}=4.81$ $\mathrm{mH}$. Asymmetry of the voltages was realized by a sequential connection of sources of symmetric sinusoidal voltages of $100 \mathrm{~V}$ in direct sequence and $20 \mathrm{~V}$ in negative sequence with values of initial phases corresponding to parameters $U_{+}=100 \sqrt{3} B ; \dot{\delta}_{-}=0.2 j . \quad$ PAF has been simulated by dependent sources of currents controlled by source voltages. In order to generate filter currents in accordance with (11) and (20), the parameters of the dependent sources were taken equal

$G_{+}=-\left(g_{+}+\Delta g\right) \delta_{-}^{2}=21.88 \times 10^{-3} G ; G_{-}=g_{+}+\Delta g=0.547 G$.

The simulation results confirmed all calculated rms currents (Table 1) and the advantages of using a hybrid filter with the proposed currents distribution.

Table 1

\begin{tabular}{|l|c|c|c|c|}
\hline & $I^{2}$ & $I_{S R}^{2}$ & $I_{S F R}^{2}$ & $I_{F}^{2}$ \\
\hline Calculated & 31751 & 9333 & 9713 & 370 \\
\hline Measured & 31920 & 9401 & 9712 & 371 \\
\hline
\end{tabular}

Conclusions. A principle of the distribution of compensating currents between the active filter and the reactive compensator of a three-phase three-wire power supply system with asymmetric sinusoidal voltages is proposed, which provides the consumption of symmetric sinusoidal source currents and minimizes the mean square value of the filter currents.

It is shown that the direct sequence active current provides a gain on the power of losses in accordance with (14) and creates a pulsation of power with amplitude in $2 /\left(1+\delta_{-}^{2}\right)$ times less than the Fryze active current.

The possibility of compensation of inactive Friyze current by reactive elements at an arbitrary combination of linear load parameters and asymmetric sinusoidal source is proved, and direct formulas for calculating the parameters of a reactive compensator for generating Fryze inactive current are obtained.

An example of simulation of currents filtration of linear stationary load showed that the combined application of PAF and reactive compensator with the proposed distribution of currents of compensation ensured reduction of energy losses in the transmission line at 3.273 times, and the relative mean square value of PAF current was $12.9 \%$ of the rms value of the total compensating current.

\section{REFERENCES}

1. Fryze S. Active, reactive and apparent power in circuits with nonsinusoidal voltage and current. Przeglad Elektrotechniczny, 1931, no.7, 8, pp. 193-203.

2. Shidlovskii A.K., Kuznetsov V.G. Povysheniye kachestva elektroenergii $v$ elektricheskikh setyakh [Improving of the power quality in electrical networks]. Kiev: Naukova Dumka Publ., 1985. 268 p.(Rus).

3. Hanzelka Z. Mitigation of voltage unbalance. Available at: http://www.leonardo-energy.org/chapter-5-mitigation-voltageunbalance (accessed 22 May 2016).

4. Czarnecki L.S., Haley P.M. Unbalanced Power in Four-Wire Systems and Its Reactive Compensation. IEEE Transactions on Power Delivery, 2015, vol.30, no.1, pp. 53-63. doi: 10.1109/TPWRD.2014.2314599.

5. Sirotin Iu.A. Fryze's compensator and Fortescue transformation. Przeglad Elektrotechniczny, 2011, no.1, pp. 101-106. 
6. Sirotin Iu.A. Non-pulsed mode of supply in a three-phase system at asymmetrical voltage. Przeglad Elektrotechniczny, 2013, no.7, pp. 54-58.

7. IEEE Std. 1459-2010. Definitions for the measurement of electric power quantities under sinusoidal non-sinusoidal, balanced or unbalanced conditions. doi: 10.1109/IEEESTD.2010.5439063.

8. Salmerón Revuelta P., Pérez Litrán S., Prieto Thomas J. Active power line conditioners design, simulation and implementation for improving power quality. Elsevier Inc.: Academic Press, 2016. 436 p.

9. Artemenko M.Y., Batrak L.M., Polishchuk S.Y., Mykhalskyi V.M., Shapoval I.A. Reactive compensation of nonactive power in hybrid shunt filter of three-phase four-wire system at random load. Proceedings of 2016 2nd International Conference on Intelligent Energy and Power Systems (IEPS). Kiev, 2016. doi: 10.1109/IEPS.2016.7521863.

10. Artemenko M.Y., Polishchuk S.Y., Mykhalskyi V.M., Shapoval I.A. Apparent power decompositions of the three- phase power supply system to develop control algorithms of shunt active filter. Proceedings of the IEEE First Ukraine Conference on Electrical and Computer Engineering (UKRCON), 2017, pp. 495-499. doi: 10.1109/UKRCON.2017.8100537.

Received 13.02.2018

M.Yu. Artemenko ${ }^{1}$, Doctor of Technical Science, Professor,

L.M. Batrak ${ }^{1}$, Candidate of Technical Science,

S.Y. Polishchuk ${ }^{2}$, Candidate of Technical Science,

${ }^{1}$ National Technical University of Ukraine «Igor Sikorsky Kyiv Polytechnic Institute»,

37, Prosp. Peremohy, Kyiv, Ukraine, 03056,

e-mail: artemenko_m_ju@ukr.net, batrakln5@gmail.com

${ }^{2}$ The Institute of Electrodynamics of the NAS of Ukraine,

56, prospekt Peremogy, Kiev-57, 03680, Ukraine,

e-mail: polischuk@ied.org.ua

How to cite this article:

Artemenko M.Yu., Batrak L.M., Polishchuk S.Y. Current filtering in a three-phase three-wire power system at asymmetric sinusoidal voltages. Electrical engineering \& electromechanics, 2018, no.2, pp. 63-68. doi: 10.20998/2074272X.2018.2.11. 